
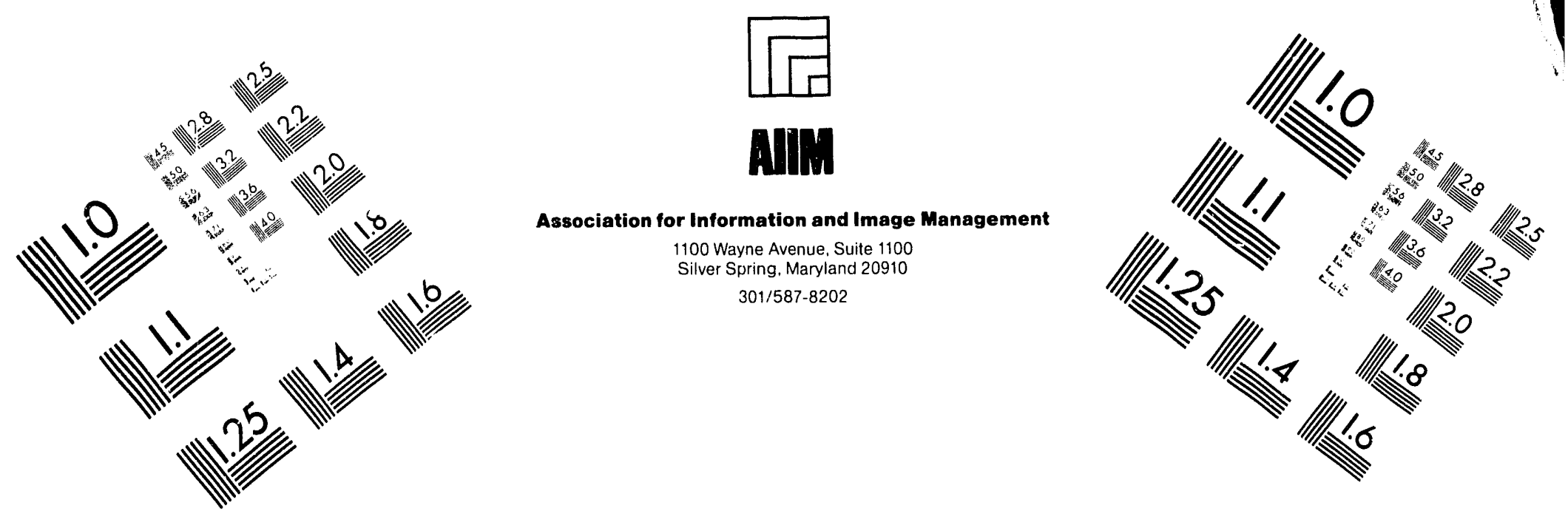

\title{
Centimeter
}

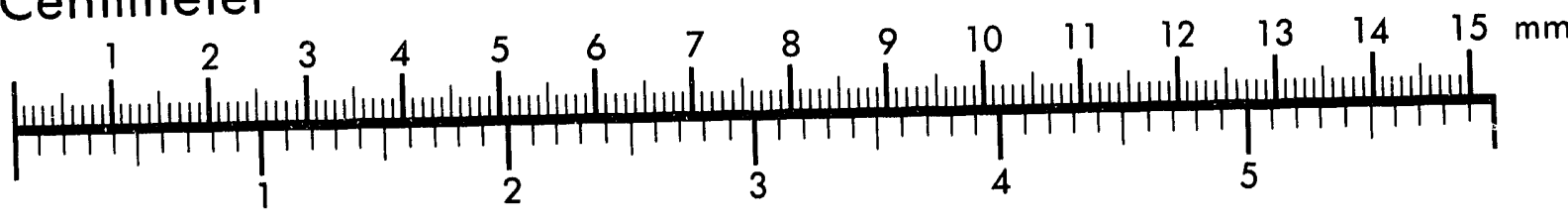
Inches
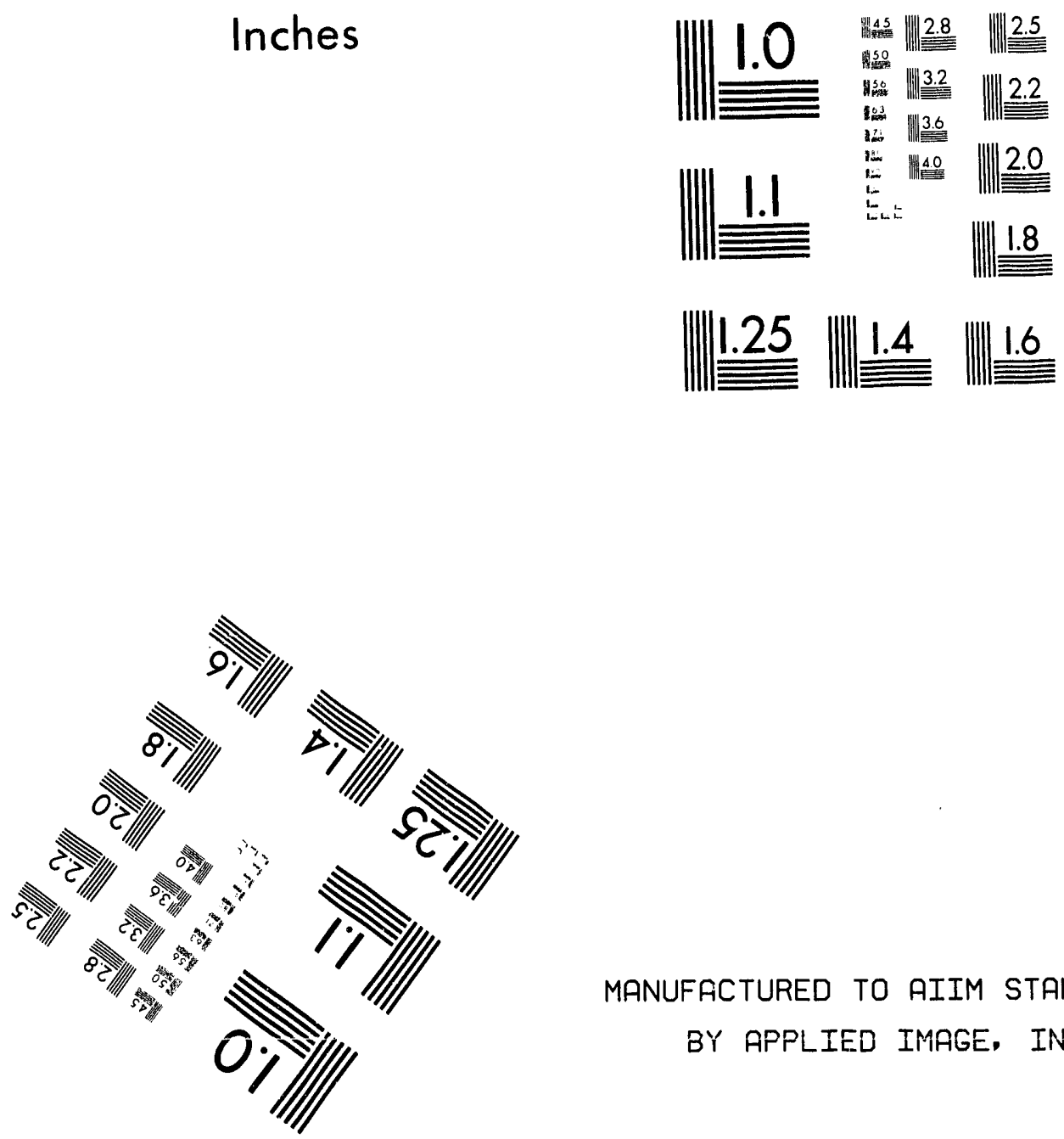

MANUFFCTURED TO AIIM STANDARDS

BY APPLIED IMAGE. INC.

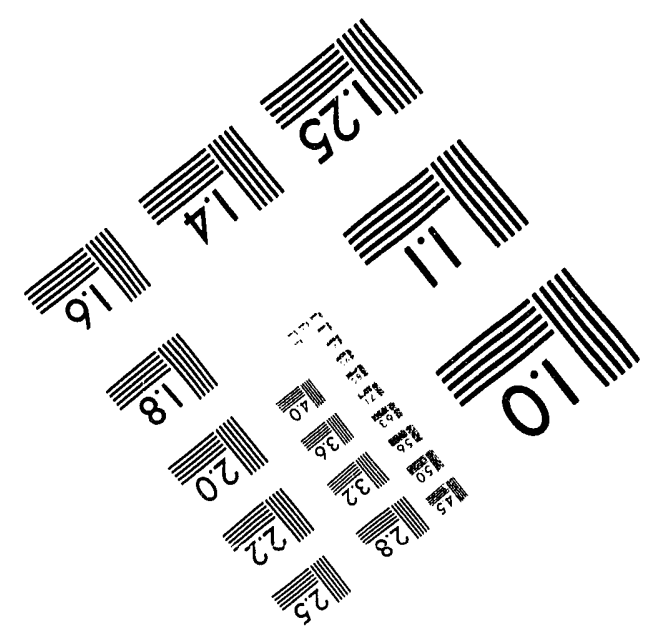



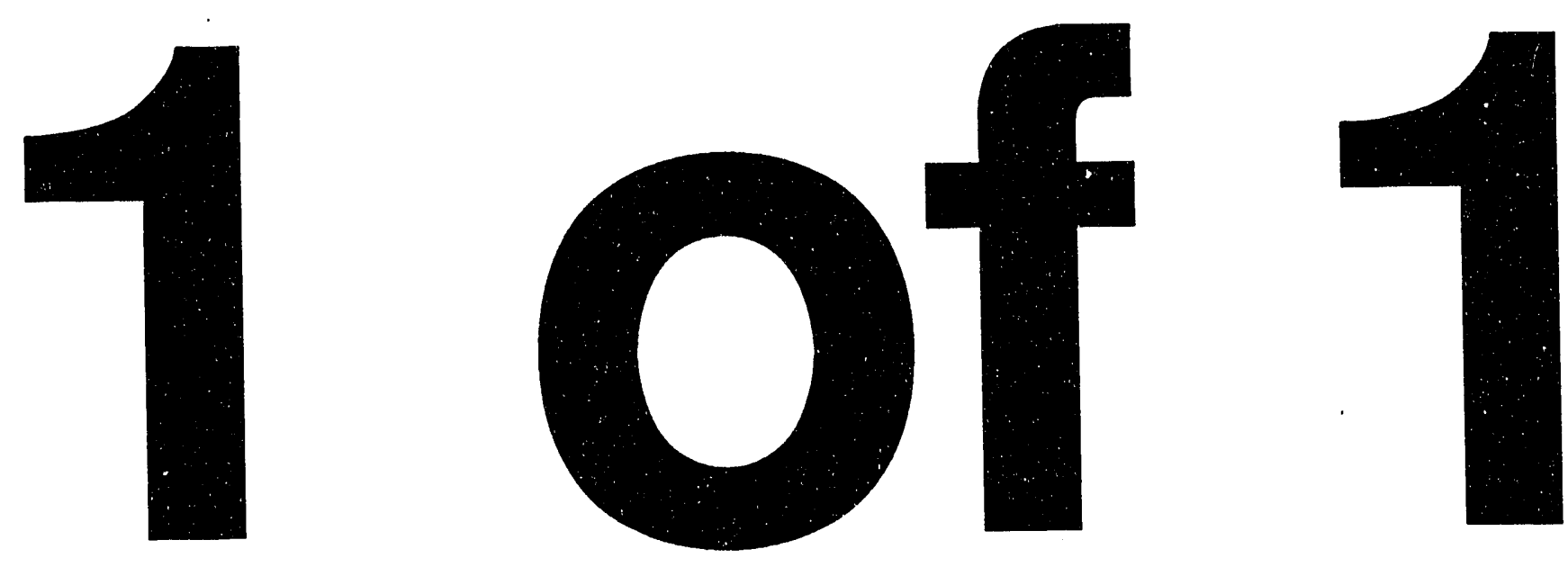
NRTSC

Technology

On Time

On Target

(6))

NUCLEAR REACTOR TECHNOLOGY

AND SCIENTIFIC COMPUTATIONS
W S R C - T R - $91-356$

KEY WORDS: Verification

Validation

Action Matrix

RETENTION PERIOD: PERMANENT

\section{GRIMHX VERIFICATION AND VALIDATION ACTION MATRIX SUMMARY (U)}

B y

E. F. Trumble

ISSUED: December 1991

WESTINGHOUSE SAVANNAH RIVER COMPANY SAVANNAH RIVER LABORATORY AIKEN, SC 29808

PREPARED FOR THE U.S. DEPARTMENT OF ENERGY UNDER CONTRACT DE-AC09 89SR18035

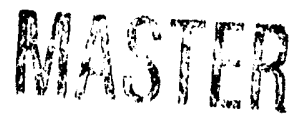


PROJECT: PHYSICS CODE CERTIFICATION

DOCUMENT: WSRC - T R -91-356

TITLE: GRIMHX VERIFICATION AND VALIDATION ACTION MATRIX SUMMARY

APPROVALS

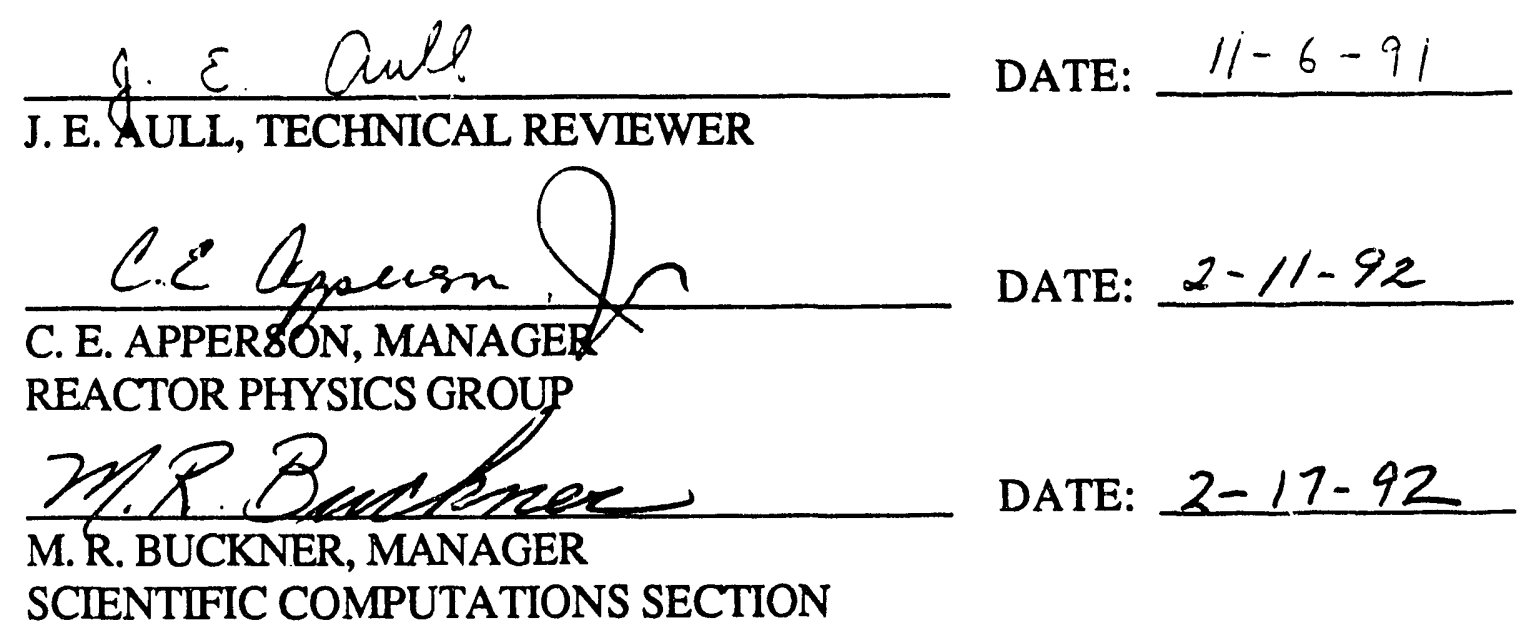




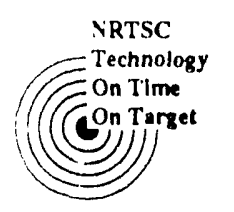

GRIMHX Verification and Validation

WSR C - TR - $91 \cdot 356$ Action Matrix Summary

\subsection{SUMMARY}

WSRC-RP-90-026, Certification Plan for Reactor Analysis Computer Codes, describes a series of action items to be completed for certification of reactor analysis computer codes used in Technical Specifications development and for other safety and production support calculations. Validation and verification of the code is an integral part of this process. This document identifies the work performed and documentation generated to satisfy these action items for the Reactor Physics computer code GRIMHX. Each action item is discussed with the justification for its completion. Specific details of the work performed are not included in this document but are found in the references. The publication of this document signals the validation and verification effort for the GRIMHX code is completed.

\subsection{INTRODUCTION}

WSRC-RP-89-1249, Verification and Validation Plan for Reactor Analysis Computer Codes, describes a series of action items to be completed for verification and validation of reactor analysis computer codes used in Technical Specifications development and for other safety and production support calculations. These requirements have been organized into an action matrix. Each action item describes the different type of information and documentation that must be assembled for each code to be certified. The action matrix serves as a useful tracking tool for monitoring completion of the certification process for individual codes.

Figure 1 shows the present status of the action matrix for the computer code GRIMHX. As can be seen in the figure, all the requirements for certification of the code have been completed with review of this document and its associated references satisfying the review process. The rest of this document gives the justification for checking each box in turn and identifies all relevant reference documentation. This material forms the basis for the required validation reviews. The action matrix (Figure 1) divides the activities into five groups: Basics, Theory, Experiments, Benchmarks, and Conclusions. The remainder of this report utilizes the same structure and format. 


\subsection{ACTION MATRIX}

\subsection{BASIC REQUIREMENTS}

\subsubsection{User's Manual in Place}

User documentation for the GRIMHX computer code is contained in the GRIMHX User's Manual (Erickson et al., 1991a.) This document provides all the necessary information for knowledgeable individuals to utilize the GRIMHX code, providing they are familiar with their computer facilities and the JOSHUA system. The manual provides a significant supplement to earlier user instructions (Honeck, 1970) which was issued only in draft form. The user's manual explains how to set up and interpret results from all of the important calculations performed using the GRIMHX code.

Chapters 1 and 2 of the user's manual present an introduction and overview of the GRIMHX code and describe the use of GRIMHX in a stand alone mode and as a module driven by other codes. Chapters 3 and 4 provide a description of the theory and programming logic of GRIMHX. Chapter 5 describes the use of the GRIMHX code, including general input information for the different calculation types. The final chapter is a description of the GRIMHX output. Following the six chapters are six appendices. These appendices provide auxiliary information, such as how to submit a GRIMHX job on the IBM or VAX computer, descriptions of subroutines and a Glossary of terms.

\subsubsection{Configuration Control Plan}

The Configuration Control Plan for the reactor analysis computer codes, including the GRIMHX code, is given in the Certification Plan for Reactor Analysis Computer Codes (Toffer et al., 1990). Configuration control of the GRIMHX code is implemented by following Procedure No. TP-90-018: Responsibilities of Technical Proprietors for Configuration Management Using SCMS.. Source coding for the J70 and J80 ("old" and "new" JOSHUA) versions of GRIMHX has been installed in SCMS. Executables for GRIMHX in J80 have been placed in production status on the IBM 3090 and the SRS VAX system. 


\subsubsection{Code Portability}

GRIMHX has been converted to standard Fortran 77, a machine independent language, however GRIMHX is intimately tied to the JOSHUA system, which is machine dependent. Therefore, the portability of GRIMHX is dependent upon the portability of the JOSHUA system. GRIMHX, and the JOSHUA system were originally written on the IBM mainframes at the SRS; currently they run on the IBM 3090. In addition, the JOSHUA system and most of the important reactor physics codes that operate under it have been converted to run on the SRS VAX network and on the Westinghouse Hanford VAX system. Further portability of GRIMHX is dependent on portability of JOSHUA. Limited portability of JOSHUA has been demonstrated and additional portability can be implemented if the need arises.

\subsection{VERIFICATION OF THEORY}

\subsubsection{Appropriate Theory}

GRIMHX solves the neutron diffusion equation for multi-group and space dependence using multi-group diffusion theory. The GRIMHX implementation assumes the solution to this equation can be discretized in both space and energy. These are all industry accepted approaches (Bell and Glasstone, 1970; Duderstadt and Hamilton, 1976; Henry, 1986; Honeck, 1972). The theory employed by the GRIMHX code is appropriate for the types of problems it is intended to solve.

\subsubsection{Theory Documented}

Detailed descriptions of solutions to the diffusion equation can be found in the open literature (Bell and Glasstone, 1970; Duderstadt and Hamilton, 1976; Henry, 1986). The GRIMHX implementation of the theory is thoroughly documented in several references (Honeck, 1972; Erickson et al., 1991a.) 


\subsubsection{Coding Consistency}

The GRIMHX code was developed long before the current validation and verification requirements were in place and as a result the verification performed at the time was not documented sufficiently to meet current requirements. Retroactively verifying line by line the coding of such a large software system as GRIMHX would be a monumental task and it has not been deemed necessary. The extensive operations history of GRIMHX in conjunction with the code validations and verifications discussed below are sufficient to establish that the code is functioning as intended; therefore this item is satisfied.

\subsubsection{Theory Verified Conceptually}

The GRIMHX code theory is summarized in several places (Honeck, 1970; Erickson et al., 1991a.) Since no new theoretical development is introduced, the basic theory as documented in the open literature and the description of the code function (Erickson et al., 1991a) provide conceptual verification of the code theory as required.

\subsubsection{Theory Verified by Experiment}

The GRIMHX code was validated against two and three dimensional space time experiments. The details of these experiments are described in the Validation and Verification Summary Report for GRIMHX (Trumble, 1990).

\subsubsection{Theory Documentation Adequate}

The theory documentation in the GRIMHX User's Manual (Erickson, et. al., 1991a) and the open literature (Honeck, 1972) is adequate for verification of the GRIMHX code. 


\subsection{VALIDATION WITH EXPERIMENTS}

\subsubsection{Tests in Experimental Facilities}

Tests have been performed in experimental facilities at SRS and elsewhere and the data have been successfully validated with the GRIMHX code (Crowe et al., 1991). In particular, experiments have been performed at the Process Development Pile (PDP) (Trumble, 1990). These facilities have provided essential data to perform validation with experimental information.

\subsubsection{Tests in Operating Facilities}

Tests in operating facilities have been performed in SRS reactors for the validation of GRIMHX (Crowe, et al., 1991). GRIMHX successfully replicated the highly space dependent chargeback problem.

\subsubsection{Data from Operating Facilities}

Operating data from previous charges run in the SRS reactors is available. These data include critical rod positions, assembly powers, and axial power shapes at various times in cycle. GRIMHX can be used to directly model operating reactors, and the GRIMHX results can then be compared to the operating data. Such comparisons have been performed (Crowe et al., 1991), and therefore validation of GRIMHX to operating facility information is considered complete.

\subsubsection{Test Data Documented}

A substantial body of data appropriate for validations has been identified and documented. This data is referenced in the two GRIMHX Verification and Validation reports (Crowe et al., 1991; Trumble, 1990). 


\subsubsection{Appropriate Data Quality}

The quality of the test data used in the validation of the GRIMHX code is described in the references given in GRIMHX Verification and Validation Report (Crowe et al., 1991). Where possible the data used has been technically reviewed and complies with appropriate QA requirements.

\subsubsection{Validation Performed}

The GRIMHX code has been validated against both experimental and operating data. The code features and models that have been validated are described in GRIMHX Verification and Validation Report (Crowe et al., 1991). Some of the earlier validation efforts are summarized in a previous validation document (Trumble, 1990). Both documents underwent independent technical review.

\subsubsection{Validation Documentation Adequate}

This item was satisfied by technical review of the two validation summary reports (Crowe, et al., 1991; Trumble, 1990).

\subsection{VALIDATION BY BENCHMARKING}

\subsubsection{Benchmark Requirements Identified}

The GRIMHX code is capable of addressing many different types of problems in reactors with hexagonal mesh. Benchmarks have been performed for the important and most commonly used GRIMHX features as reported in the verification and validation report (Crowe et al., 1991).

\subsubsection{Similar Code Comparison}

The industry standard code, MCNP (Briesmeister, 1986) is capable of solving similar types of problems as GRIMHX. MCNP is a Monte Carlo code and its solution method and cross section libraries differ from those employed by GRIMHX. In general, Monte Carlo solutions employ fewer approximations than other methods and thus can provide a more exact 
solution. The MCNP code was successfully used in inter-code comparisons with GRIMHX. The results of these comparisons are summarized in the validation and verification report (Crowe et al., 1991).

\subsubsection{Exact Solution Comparison}

It is not possible to produce an exact solution for the complex problems GRIMHX solves. This item is not required for validation because other means of validation have been demonstrated.

\subsubsection{Industry Benchmark Comparisons}

The GRIMHX code has been successfully compared to 2-D and 3-D benchmarks with the results of these comparisons described in the GRIMHX Verification and Validation Report (Crowe et al., 1991).

\subsubsection{Comparisons Documented}

The results of the successful benchmarking are documented in the GRIMHX Benchmarking Report (Erickson et al., 1991b.)

\subsubsection{Benchmark Documentation Adequate}

The benchmarking of GRIMHX is described in both the GRIMHX Benchmarking Report (Erickson et al., 1991b) and the GRIMHX Verification and Validation Summary Report (Crowe et al., 1991). These two documents provide adequate documentation.

\subsubsection{Verification Review}

The technical review of the GRIMHX Verification and Validation Summary Report (Crowe, et al., 1991) satisfies the verification review.

\subsubsection{Verification Completed}

The technical review of the GRIMHX Verification and Validation Summary Report (Crowe, et al., 1991) completes the verification process. 


\subsection{CONCLUSIONS}

\subsection{Standard Set of Test Problems}

A standard set of test problems has been developed and documented (Le, 1991 ).

\subsection{Validation/Benchmarking Review}

The technical review of the GRIMHX Verification and Validation Summary Report (Crowe, et al., 1991) and the GRIMHX Benchmarking Report (Erickson, et al., 1991b) satisfies the validation/benchmarking review.

\subsection{Validation/Benchmarking Completed}

The technical review of the GRIMHX Verification and Validation Summary Report (Crowe, et al., 1991) and the GRIMHX Benchmarking Report (Erickson, et al., 1991b) signals the completion of the validation/ benchmarking process. 


\section{Figure 1}

\section{Verification and Validation Plan Action Matrix for GRIMHX}

Basics

User Manuals in Place

Configuration Control Plan

Code Portability

Theory

Appropriate Theory

Theory Documented

Coding Consiatency

Theory Verified Conceptually

Theory Verified by Experiments

Theory Documentation Adequate

Tests in Experimental Facilities

Test in Operating Facilities

Experiments

Data from Operating Facilities

Test Data Documented

Appropriate Data Quality

Validation Performed

Validation Documentation Adequate

Benchmark Requirements Identified

Similar Codo Comparison

Exact Solution Comparison

Benchmarks

Industry Benchmark Comparison

Comparieons Documented

Benchmark Documentation Adequate

Verification review

Verification Completed

Conclusions

Standard Set of Teat Problems

Validation/Benchmarking Review

Validation/Benchmarking Completed 


\subsection{REFERENCES}

Argonne National Laboratory, National Energy Software Center: Benchinark Problem Book, ANL-7416 Supplement 3 (DE86012678), December 1985.

Bell, G.I., Glasstone, S., Nuclear Reactor Theory, Van Nostrand, Princeton, N.J., 1970.

Briesmeister, J.F., Editor, MCNP - A General Monte Carlo Code for Neutron and Photon Transport, Version 3B5, LA-7396-M, Rev. 2, 1986.

Crowe, R.D., H. Toffer and E.F. Trumble, GRIMHX Verification and Validation Summary Report, WSRC-TR-91-358, 1991.

Duderstadt, J.J., Hamilton, L.J., Nuclear Reactor Analysis, John Wiley \& Sons, New York, 1976.

Erickson, D. G., R.D. Crowe, E.F. Trumble, GRIMHX User's Manual, WSRC-TR91-354, (1991a.)

Erickson, D. G., R. D. Crowe, S. H. Finfrock, and E. F. Trumble, GRIMHX Benchmarking Report, WSRC-TR-91-359, (1991b.)

Henry, A. F., Nuclear-Reactor Analysis, The MIT Press, Cambridge, MA, USA, 1986.

Honeck, H. C., The JOSHUA System, DPSTM-500, Vols. 10.1, DRAFT, 1970.

Honeck, H.C., J.W. Stewart, Simultaneous Line Over-Relaxation (SLOR) in Hexagonal Lattice, DPST-MS-72-27, 1972.

Jensen, J.C., Responsibilities of Technical Proprieinrs for Configuration Management Using SCMS, TP-90-018, November 1990.

Le, T. T., A Standard Set of Test Problems for GRIMHX, SCS-RPG-91-0273, 1991. 
Toffer, H., R.D. Crowe, K.N. Schwinkendorf, R.E. Pevey, Verification and Validation Plan for Reactor Analysis Computer Codes (U), WSRC-RP-891249, 1989.

Toffer, H., R.D. Crowe, K.N. Schwinkendorf, R.E. Pevey, Certification Plan for Reactor Analysis Computer Codes, WSRC-TR-90-26, 1990.

Trumble, E.F., Validation and Verification Summary Report for GRIMHX and TRIMHX, WSRC-TR-90-594, December 1990. 

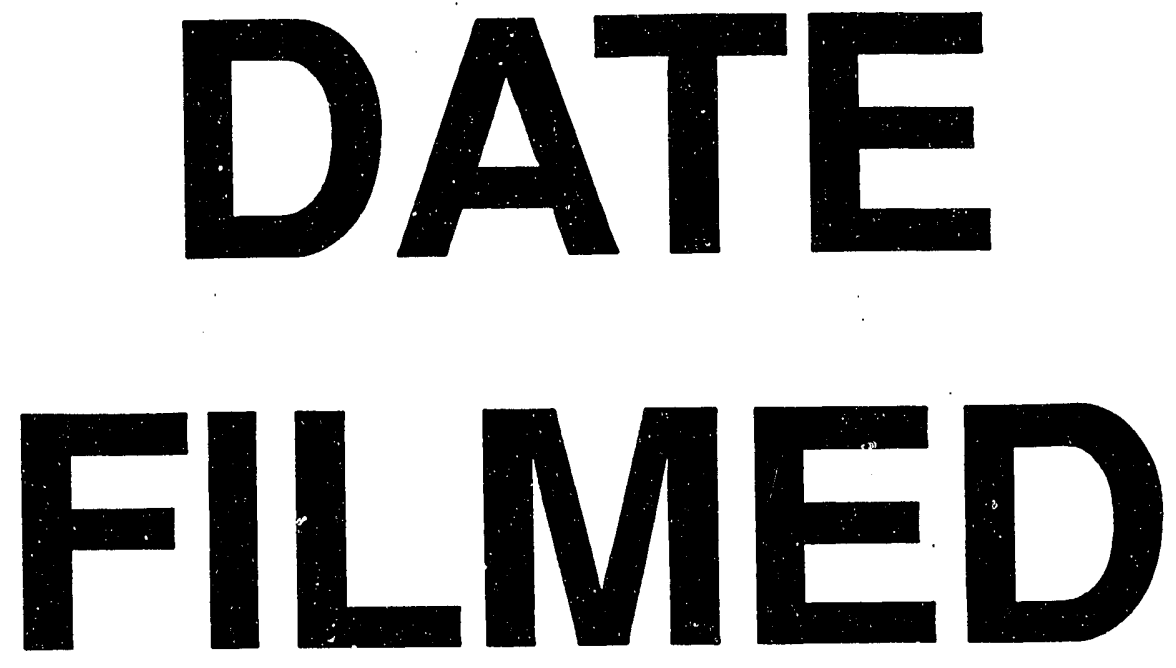

$8 / 19 / 93$
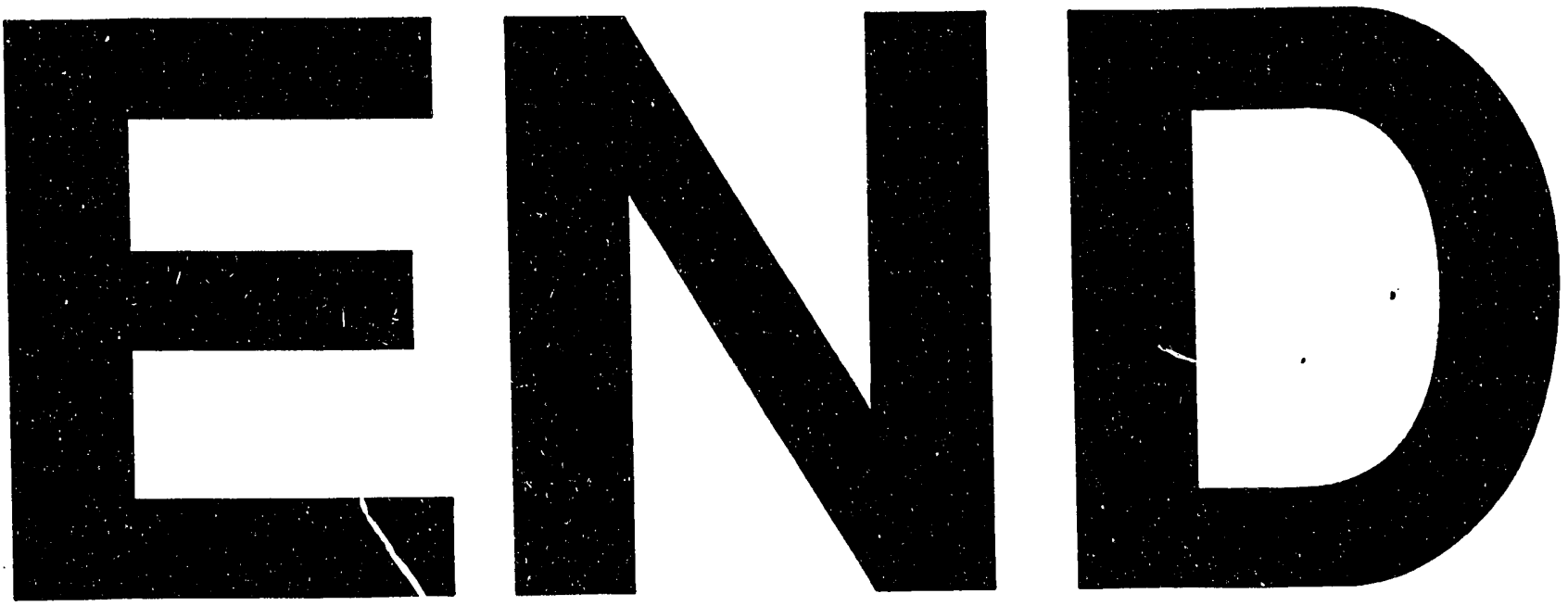


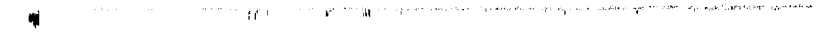

